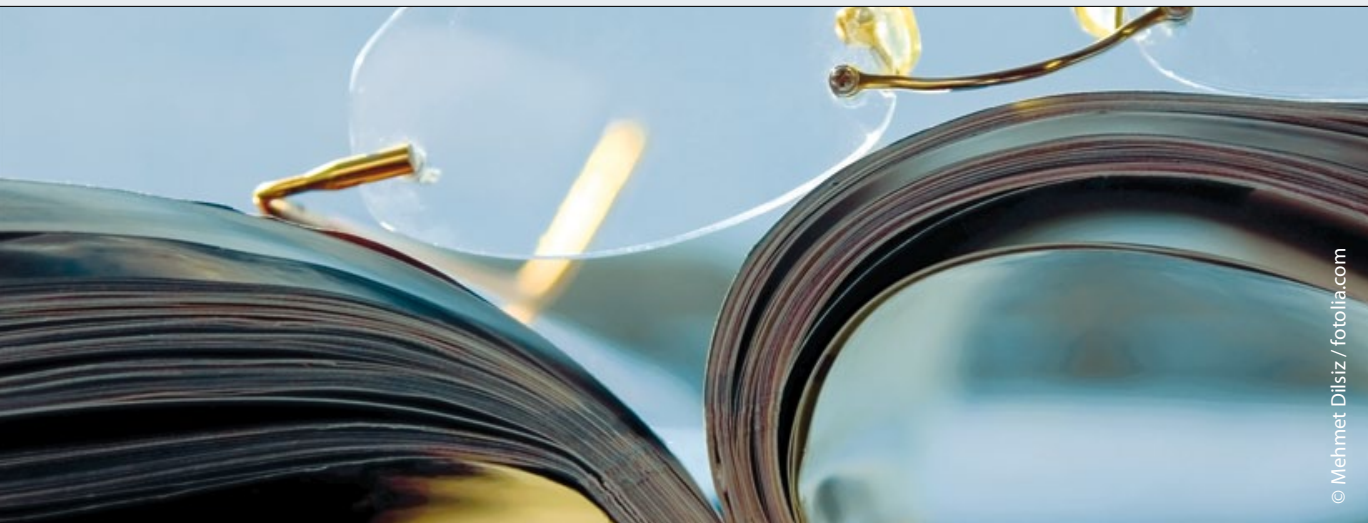

\title{
Wer spricht mit dem Patienten übers Lebensende?
}

Schwerkranke Patienten haben das Recht, den Umgang mit ihrem Lebensende selbst zu bestimmen. Aber hat der Patient auch die Chance, seine Wünsche wie etwa den Sterbeort rechtzeitig zu äußern?

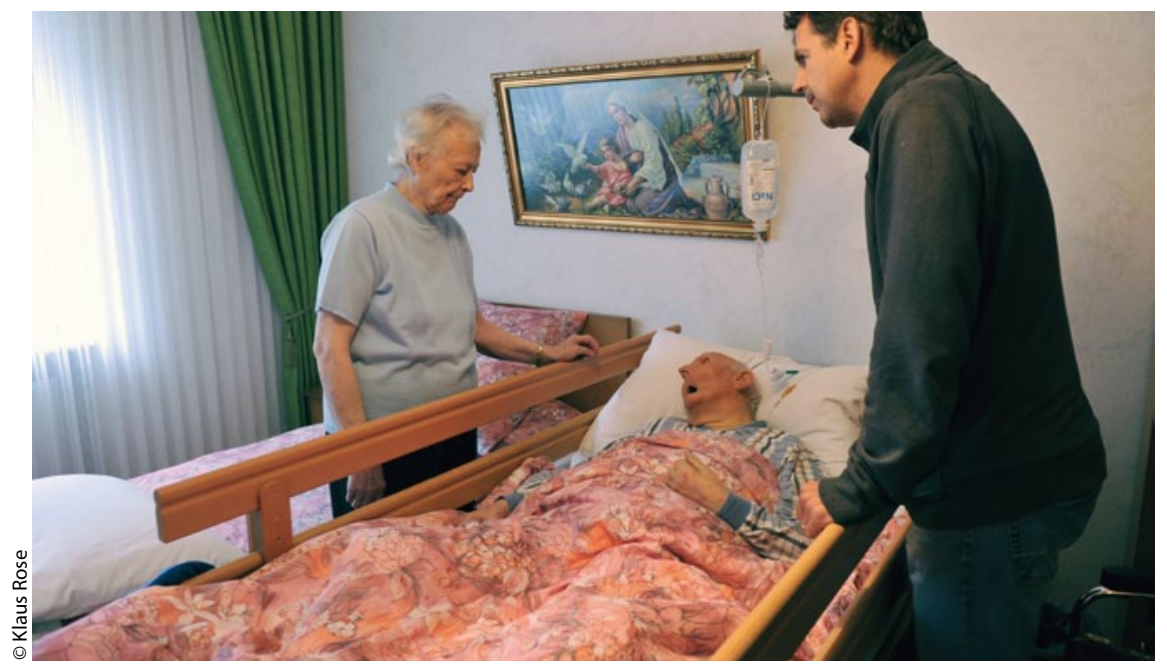

Zuhause sterben - ein Wunsch vieler Patienten

S-amerikanische Forscher befragten Patienten mit metastasierenden Lungen- oder kolorektalen Karzinomen des Stadiums IV und einer Lebenserwartung von 4-8 oder 12-24 Monaten im Verlauf ihrer Erkrankung, ob, mit wem, wo und zu welchem Zeitpunkt ihre Wünsche und Präferenzen für den weiteren Verlauf und die Behandlung besprochen wurden. Falls die Patienten wegen ihres Befindens nicht befragt werden konnten oder in der Zwischenzeit verstorben waren, dienten die Krankenakten oder Angehörige als Informationsquelle.
Die letzten Wünsche waren mit $73 \%$ der Patienten diskutiert worden, und zwar mit $41 \%$ derjenigen, die zum Zeitpunkt der Nachbefragung noch lebten, und mit $87 \%$ derjenigen, die inzwischen verstorben waren. Bei $55 \%$ der Patienten erfolgte dies in der Klinik. Der Zeitpunkt lag im Mittel 33 Tage vor dem Tod, naturgemäß mit Schwankungen zwischen 14 und 69 Tagen in Abhängigkeit von der Überlebensdauer zwischen weniger als einem und mehr als zwölf Monaten. Am häufigsten wurden die Themen Verlegung in ein Hospiz, Reanimation und Palliativbe- handlung, nur selten der Wunsch nach dem Sterbeort besprochen.

Kommentar: Nach den Empfehlungen von Fachgesellschaften sollen die Wünsche für das Lebensende mit Patienten besprochen werden, wenn die Lebenserwartung weniger als ein Jahr beträgt. Nach Daten von 2011 wurden solche Gespräche bisher nur bei etwa $40 \%$ der Patienten geführt. In der vorliegenden Erhebung aus den USA liegt diese Rate bei Patienten mit inkurablem Lungen- oder Dickdarmkarzinom etwa doppelt so hoch. Allerdings wurden die meisten Gespräche erst wenige Wochen vor dem Tod geführt, nicht aber während stabiler Krankheitsphasen, also vermutlich nachdem viele Therapieentscheidungen schon getroffen und bevor die grundsätzlichen Wünsche für das Lebensende diskutiert wurden. Patienten wählen in solchen Gesprächen eher eine palliative als eine aggressive Therapie und wünschen vorzugsweise $\mathrm{zu}$ Hause oder in einem Hospiz, nicht aber in einer Klinik zu sterben.

Vorzugsweise sollten nicht die Onkologen das Gespräch mit den Patienten über die Wünsche am Lebensende suchen, sondern die Ärzte, die eine enge und lange Beziehung zu ihren Patienten haben - und gerade deshalb diese Aufgabe oftmals zu vermeiden suchen. Vor allem sollten diese Gespräche schon nach der Diagnose eines inkurablen Malignoms erfolgen, und nicht erst durch akute, schwere Komplikationen angestoßen werden.

Prof. Heinrich Holzgreve

Mack JW et al. End-of-life care discussions among patients with advanced cancer. Ann Intern Med 2012; 156: 204-10 